\title{
Microbial community dynamics of surface water in British Columbia, Canada
}

Miguel I. Uyaguari-Diaz ${ }^{1,2^{*}, \# \mathrm{a}}$, Matthew A. Croxen ${ }^{1,2^{*}, \# \mathrm{~b}, \# \mathrm{c}}$, Kirby Cronin ${ }^{1, \# \mathrm{~d}, \# \mathrm{e}}$, Zhiyao Luo ${ }^{2, \# \mathrm{f}}$, Judith Isaac-Renton ${ }^{1,2}$, Natalie A. Prystajecky ${ }^{1,2^{\wedge}}$, Patrick Tang ${ }^{1,2, \# \mathrm{~g}, \# \mathrm{~h}^{\wedge}}$

${ }^{1}$ Department of Pathology and Laboratory Medicine, Faculty of Medicine, The University of British Columbia

${ }^{2}$ British Columbia Centre for Disease Control Public Health Laboratory

${ }^{\# a}$ Current address: Department of Microbiology, University of Manitoba, Winnipeg, Manitoba, Canada R3T 2N2

${ }^{\# \mathrm{~b}}$ Current address: Provincial Laboratory for Public Health, Edmonton, Alberta, Canada T6G 2J2

${ }^{\# c}$ Current address: Department of Laboratory Medicine and Pathology, University of Alberta, Edmonton, Alberta, Canada, T6G 2R7

${ }^{\# d}$ Current address: Public Health Ontario Laboratories, Toronto, Ontario, Canada M5G 1M1

${ }^{\text {\#e}}$ Current address: National Microbiology Laboratory, Public Health Agency of Canada, Winnipeg, Manitoba, Canada R3E 3R2

${ }^{\# C}$ Current address: British Columbia Cancer Agency, Provincial Health Services Authority, Vancouver, Canada V5Z 4E6

${ }^{\# \mathrm{~g} C u r r e n t}$ address: Department of Pathology, Sidra Medicine, Doha, Qatar

${ }^{\# h}$ Current address: Department of Pathology and Laboratory Medicine, Weill Cornell Medicine, Doha, Qatar

$\wedge$ Corresponding authors Email:ptang@sidra.org Email: natalie.prystajecky@bccdc.ca

* These authors contributed equally to this work. 


\section{Abstract}

39 Traditional methods for monitoring the microbiological quality of water focus on the detection of fecal indicator bacteria such as Escherichia coli, often tested as a weekly grab sample. To

41 understand the stability of E.coli concentrations over time, we evaluated three approaches to

42 measuring E. coli levels in water: microbial culture using Colilert, quantitative PCR for uidA and

43 next-generation sequencing of the $16 \mathrm{~S}$ rRNA gene. Two watersheds, one impacted by

44 agricultural and the other by urban activities, were repeatedly sampled over a simultaneous ten-

45 hour period during each of the four seasons. Based on 16S rRNA gene deep sequencing, each

46 watershed showed different microbial community profiles. The bacterial microbiomes varied

47 with season, but less so within each 10-hour sampling period. Enterobacteriaceae comprised

48 only a small fraction $(<1 \%)$ of the total community. The qPCR assay detected significantly

49 higher quantities of E. coli compared to the Colilert assay and there was also variability in the

50 Colilert measurements compared to Health Canada's recommendations for recreational water

51 quality. From the 16S data, other bacteria such as Prevotella and Bacteroides showed promise as

52 alternative indicators of fecal contamination. A better understanding of temporal changes in

53 watershed microbiomes will be important in assessing the utility of current biomarkers of fecal

54 contamination, determining the best timing for sample collection, as well as searching for

55 additional microbial indicators of the health of a watershed. 


\section{Introduction}

58 The use of Escherichia coli as a fecal bacterial indicator in water is widely-adopted but also

59 contentious (Ferguson \& Signoretto 2011; Isobe et al. 2004; Rochelle-Newall et al. 2015). As a

60 species, E. coli is extremely diverse in its ability to colonize a wide range of hosts and in the

61 range of diseases it can cause (Croxen \& Finlay 2010; Kaper et al. 2004). Since E. coli colonizes

62 the gastrointestinal tract of most birds and animals, and is readily culturable from feces, it seems

63 to be well suited as an indicator of fecal contamination. Many regulatory bodies around the

64 world use $E$. coli as an indicator of water quality and the amount of $E$. coli cultured from water is

65 used as an actionable metric to enact decisions on boil water advisories or beach closures. A

66 major problem with E. coli as an indicator organism, however, is the limited amount of

67 information that can be derived from a positive- or negative-culture result. While a positive

68 result may be indicative of recent fecal pollution or also represent environmental re-growth from non-recent fecal deposition, it does not provide information on the source of contamination or on

70 the risk to health. A negative result does not rule out other pathogens such as viruses or protozoa,

71 exemplified by an outbreak in Wisconsin, where over an estimated 400,000 people fell ill due to

72 Cryptosporidum parvum oocysts present in municipal waters; this despite treated water samples

73 testing negative for coliforms (Mac Kenzie et al. 1994). Furthermore, while the ability of E. coli

74 to survive in the environment appears poor under simulated conditions (van Elsas et al. 2011),

75 there have reports of Escherichia spp. naturally present in the environment (phenotypically

76 identical to E. coli) (Byappanahalli \& Fujioka 1998; Clermont et al. 2011; Walk et al. 2009).

77 These issues raise questions about the usefulness of E. coli for routine water quality testing purposes. 
79 Routine water quality testing involves the collection of a water sample ("grab sample") and

80 culturing it for a fecal bacterial indicator such as E. coli. Culture-positive results are then

81 reported either as a single maximum concentration or as a geometric mean over a defined

82 sampling period (BC 2017). How representative one result, from one sampling event or averaged

83 from previous week's results, is uncertain. Culture of two separate $100 \mathrm{ml}$ water samples

84 collected at the same time may yield different E. coli results (Wohlsen et al. 2006). Whether this

85 is merely representative of a minor, culturable community member, such as E. coli, or true for

86 the entire community, is not yet known.

87 It is important to protect watersheds as deterioration of their health impacts the environment and

88 inter-connected ecosystems. A large metagenomics project was carried out to develop

89 biomarkers to better measure water health compared to current methods

90 (www.watersheddiscovery.ca). The work presented here provides a foundation to better

91 understand the dynamics of source water microbial communities over the course of a day, and

92 during four quarters throughout the year.

\section{Materials and methods}

\section{Water sample collection}

95 Two source waters were chosen from the lower mainland area of British Columbia. The first site

96 is a slough that runs through dairy, poultry and produce farms and is impacted by agricultural

97 land use. The second site is impacted by urban land use; it runs through an urban development

98 and includes parkland that is used for recreational purposes. Sampling days were on January $29^{\text {th }}$,

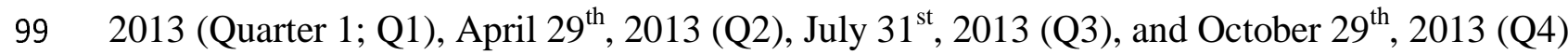


100

101

102

103

104

105

106

107

108

109

110

111

112

113

114

115

116

117

118

119

120

121

with typical weather patterns for the area. The first set of samples was collected at 08:00 Pacific

Standard time (PST), followed by a second set collected 10 minutes later (08:10 PST). Collection of water in this manner occurred every two hours until 18:10 PST. At each time point, four samples were collected in succession; two $250 \mathrm{ml}$ samples were collected for filtration in $250 \mathrm{ml}$ wide mouth translucent HDPE bottles. Two additional samples were collected for Colilert (IDEXX, Westbrook, ME) in narrow mouth $250 \mathrm{ml}$ high-density polyethylene bottles containing sodium thiosulfate (Systems Plus, Baden, ON). Samples were kept on ice throughout the day, stored at $4{ }^{\circ} \mathrm{C}$ overnight, and processed within 24 hours. In total, 48 samples ( 24 for filtration and 24 for Colilert) were collected at each site, per day for an overall total of 196 filtration samples (24 samples x 2 sites x 4 sampling days) and 196 Colilert samples.

\section{Water filtration, coliform and $E$. coli counts}

One hundred milliliters (ml) of water were filtered using 0.2- $\mu \mathrm{m}$ 47-mm Supor-200

polyethersulfone membrane disc filters (Pall Corporation, Ann Harbor, MI) inserted into $300 \mathrm{ml}$ Pall $47 \mathrm{~mm}$ magnetic polyphenylsulfone filter funnels (Pall Corporation, Ann Harbor, MI). The filters were rolled up and stored at $-20^{\circ} \mathrm{C}$ until needed for nucleic acid extraction. A negative filtration control was also processed using MilliQ water (Millipore Corporation, Billerica, MA). Dilutions were conducted from the bottles containing sodium thiosulfate (1:10 for the urban site, 1:100 for the agricultural site) and $100 \mathrm{ml}$ of diluted sample was poured into a Colilert QuantiTray/2000 (IDEXX). Trays were sealed according to manufacturer's instructions and incubated at $37^{\circ} \mathrm{C}$. Yellow (coliforms) and blue fluorescent wells (E. coli) were enumerated after 24 hours of incubation, and used to calculate the most probable number (MPN) according to the table provided with the Colilert kit. MilliQ water was used as a negative control. 


\section{Nucleic acid extraction, 16S rRNA gene amplification and sequencing}

123 Following filtration polyethersulfone membrane disc filters were cut into four pieces. Nucleic

124 acids were extracted from each quarter filter using the MO BIO PowerLyzer PowerSoil DNA

125 Extraction Kit (MoBio, Carlsbad, CA) according the manufacturer's instructions. Extracted

126 DNA samples from each quarter filter were pooled and further concentrated using 0.1 volumes

127 of $3 \mathrm{M}$ sodium acetate, two volumes of $100 \%$ ethanol, and $5 \mu \mathrm{l}$ of $5 \mu \mathrm{g} / \mu \mathrm{l}$ linear acrylamide.

128 Eluents were stored at $-80{ }^{\circ} \mathrm{C}$ overnight, and then centrifuged at $17,000 \times \mathrm{g}$ for $30 \mathrm{~min}$ at $4{ }^{\circ} \mathrm{C}$.

129 Supernatants were discarded, and pellets were washed with $70 \%$ ice-cold ethanol, air dried, and

130 resuspended in $34 \mu \mathrm{l}$ of $10 \mathrm{mM}$ Tris, $\mathrm{pH}$ 8.5. One $\mu \mathrm{l}$ of DNA from each extract was used to

131 amplify the V4 region (515F: 5'- GTGCCAGCMGCCGCGGTAA-3' and 806R: 5' -

132 GGACTACHVGGGTWTCTAAT-3') of the 16S ribosomal RNA (ca. 253 bp) using GoLay

133 primers as previously described (Caporaso et al. 2012). These GoLay primers add compatible

134 adapters and barcodes for the Illumina MiSeq and HiSeq sequencing platforms. The negative

135 processing control was also included in the PCR amplification, as well as a mock community

136 that consisted of E. coli, Pseudomonas putida, P. aeruginosa, P. fluorescens, Burkholderia

137 cenocepacia, Bacillus amyloliquefaciens, B. cereus, Rhodobacter capsulatus, Streptomyces

138 coelicolor, Micrococcus luteus, and Frankia sp. CcI3 as described earlier (Peabody et al. 2015).

139 Amplicons were purified using the QIAgen QIAquick PCR purification kit according to

140 manufacturer's instructions. Purified PCR products were quantified using Qubit dsDNA HS

141 Assay Kit (Invitrogen). Each amplicon from a single sampling day (24 agricultural, 24 urban, 1

142 negative control and, 1 mock community) was pooled together for a final equimolar

143 concentration of $4 \mathrm{nM}$. Each pool (4 total) was diluted to a final loading concentration of 11.5

$144 \mathrm{pM}$, and PhiX at $8 \mathrm{pM}$ was spiked in at 30\%. Each pool was run individually on an Illumina 
MiSeq (Illumina, Inc., San Diego, CA) using the 300-cycle (2 x 150 bp) MiSeq Reagent Kit v2 (Illumina). Immediately prior to sequencing, additional primers $(100 \mu \mathrm{M})$ were added to the MiSeq reagent cartridge as follows: $3.4 \mu 1$ of Read 1 sequencing primer to reservoir $12 ; 3.4 \mu 1$ of Index sequencing primer to reservoir $13 ; 3.4 \mu$ of Read 2 sequencing primer to reservoir 14 (Caporaso et al. 2012).

\section{Quantitative PCR for $E$. coli}

Quantitative PCR (qPCR) was used to target the $\beta$-glucuronidase gene (uidA) of E. coli and Shigella spp., and amplified an 84 bp product. The oligonucleotides 784F (5'-

\section{GTGTGATATCTACCCGCTTCGC-3'), 866R (5'-GAGAACGGTTTGTGGTTAATCAGGA-} 3') and TaqMan probe EC807 (5'-FAM-TCGGCATCCGGTCAGTGGCAGT-BHQ1-3') have been previously described (Frahm \& Obst 2003), except TAMRA was replaced with the BHQ1 quencher. All oligonucleotides were purchased from Integrated DNA Technologies (IDT, Inc., Coralville, IA).

Each qPCR reaction was done in a $20 \mu \mathrm{l}$ volume which consisted of $2 \mu \mathrm{l}$ of template, $1 \mathrm{X}$ PerfeCTa qPCR ToughMix, UNG, Low ROX (Quanta), $0.4 \mu \mathrm{M} 784 \mathrm{~F}$, and $0.4 \mu \mathrm{M}$ 866R. Template DNA was diluted 10-fold for agricultural samples, while template DNA from urban samples were not diluted. Amplification was performed on MicroAmp Fast Optical 96-Well Reaction Plates (Life Technologies, Carlsbad, CA) on an Applied Biosystems 7500 Real-Time PCR System (Applied Biosystems). The following cycling conditions were used: $45^{\circ} \mathrm{C}$ for 5 minutes, $95{ }^{\circ} \mathrm{C}$ for 3 minutes, then 40 cycles of $95{ }^{\circ} \mathrm{C}$ for 15 seconds and $60{ }^{\circ} \mathrm{C}$ for 1 minute. A standard curve was included in each qPCR run on 10 -fold serial dilutions $(1,740,000$ to 174 copies) of genomic DNA from E. coli ATCC 25922 that was extracted using the QIAgen 
167

168

169

170

171

172

173

174

175

176

177

178

179

180

181

182

183

184

185

186

187

188

QIAamp DNA Mini Kit (Qiagen Sciences, Inc., Germantown, MD) according to the manufacturer's protocol. Each sample was run in duplicate, while standards were run in triplicate. Gene copy numbers were normalized per $100 \mathrm{ml}$ of sample.

\section{S rRNA gene qPCR assay}

To estimate bacterial copy number in water samples, copy numbers of a 16S rRNA gene fragment ( $352 \mathrm{bp}$ ) of were calculated as described by Ritalahti et al. (2006). Primers Bac1055YF (5' - ATGGYTGTCGTCAGCT-3') (Ferris et al. 1996; Ritalahti et al. 2006) and Bac1392R (5' - ACGGGCGGTGTGTAC-3') (Lane 1991) were used in combination with Probe Bac1115 containing a 5' 6-FAM dye (CAACGAGCGCAACCC) (Harms et al. 2003; Lane 1991) with an internal ZEN quencher and a 3' Iowa Black fluorescent quencher (Life Technologies, Carlsbad, CA). Due to multiple copy nature of the $16 \mathrm{~S}$ rRNA gene in a bacterium, copy numbers were normalized by a factor of 4.3 (Lee et al. 2009) per $100 \mathrm{ml}$ of sample. E. coli genomic DNA was used for standard curves for $16 S$ rRNA gene. Each $20 \mu \mathrm{l}$ real-time PCR reaction consisted of $10 \mu \mathrm{l}$ of ABI TaqMan universal master mix (Life Technologies, Carlsbad, CA), $0.4 \mu \mathrm{M}$ of each primer, $0.1 \mu \mathrm{M}$ of probe and template DNA. DNA samples from agricultural site were diluted 1:10 using nuclease free-water (Promega Corporation, Fitchburg, WI), while that 1 to $2 \mu \mathrm{l}$ of undiluted template DNA were used for urban water samples, and $1 \mu$ l. Quantitative PCR reactions were conducted on an Applied Biosystems 7500 Fast real-Time PCR system (Life Technologies, Carlsbad, CA). The thermal cycling conditions consisted of incubation for 2 min at $50{ }^{\circ} \mathrm{C}$, initial denaturation for $10 \mathrm{~min}$ at $95^{\circ} \mathrm{C}$ followed by 40 cycles of $15 \mathrm{~s}$ at $95{ }^{\circ} \mathrm{C}$ and $60 \mathrm{~s}$ at $60{ }^{\circ} \mathrm{C}$. Standards were run in triplicate, while that environmental samples were run in duplicate. 


\section{Sequence analysis}

Demultiplexed forward and reverse reads were error corrected using BayesHammer (Nikolenko et al. 2013), followed by adapter and primer trimming, and quality filtering using Trimmomatic v0.32 (Bolger et al. 2014). Trimmed and filtered reads were assembled using PANDAseq v2.2 (Masella et al. 2012), and any assembled sequences under 220 nucleotides were discarded. The QIIME v1.9.1 package (Caporaso et al. 2010b) was used to compare the microbial communities based on 16S sequences. We used UCLUST (Edgar 2010) to pick Operational Taxonomic Units (OTU) by following a workflow for open-reference clustering (Rideout et al. 2014) at 97\% using the GreenGenes v13_8 database (DeSantis et al. 2006). After OTU picking, OTUs with abundances less than $0.005 \%$ were removed as recommended by Bokulish et al. (Bokulich et al. 2013). ChimeraSlayer (Haas et al. 2011) was used to identify chimeras and the remaining OTUs were aligned using PyNast (Caporaso et al. 2010a) before a phylogenetic tree was constructed using FastTree2 (Price et al. 2010). Bray-Curtis dissimilarity was used to determine beta diversity for each sample. Figures were generated with QIIME, R (ggplots2) (Wickham 2009), and hclust2 (https://bitbucket.org/nsegata/hclust2).

\section{Data analysis}

All data were $\log _{10}$ transformed for analysis. Spearman's rank correlation analysis was conducted among variables. Paired t-tests were used to assess differences between qPCR and Colilert assays. Data was analyzed using Statistical Analysis System (SAS, version 9.1 for Windows). A p-value of 0.05 was assumed for all tests as a minimum level of significance.

\section{Data availability}


210

211

212

213 Results and discussion

215 The lower mainland of British Columbia (BC) has temperate weather. We chose two study

216 watersheds that are impacted differently; one is impacted by farming land use (Agricultural;

217 AGR), and one has more anthropogenic impact through proximity to residential and recreational

218 land use (Urban; URB). Fig 1 represents AGR and URB sites with land cover. Distance between

219 these non-connected watersheds is $\sim 65 \mathrm{Km}$.

220 E. coli counts in watershed samples can range depending on sampling event

221 and time

222 We collected surface water samples during the winter (Q1), spring (Q2), summer (Q3) and fall

223 (Q4). We recognized that due to the single sampling event, these results are still a snapshot in

224 that particular quarter of the year and should not be interpreted as representative of an entire

225 season, or even reflective of a typical season in the study area. As well, we collected samples

226 during a defined daily period. Water samples for assessing water quality in British Columbia are

227 typically collected once a week for $E$. coli culture. To also assess the variability of $E$. coli counts

228 in the agricultural- and urban-impacted watershed study sites, we collected samples in duplicate,

229 followed in duplicate again 10 minutes later every two hours, from 08:00 hrs until 18:00 hrs. 
Agreement between duplicate samples varied; sometimes samples did not differ, when other samples were processed within 24 hours. No significant differences in counts of E. coli and total

Maier et al. 2015; Pope et al. 2003).

\section{Comparison of E.coli counts and uidA gene quantitative PCR assay}

247 We then compared the number of viable $E$. coli cells to the single copy uidA gene, detected by qPCR. There was a moderate positive correlation between the culturable $E$. coli and the qPCR 
253 2011), this qPCR assay detects DNA from viable, viable but non-culturable, as well as dead

254 cells. When compared to other studies (Noble et al. 2010; Oliver et al. 2016), this association

255 seems to be low, however a drop in correlation coefficients have been reported in environmental

256 water samples (Walker et al. 2017).

257

258 Microbial community diversity differ in the long-term, but not short-term

259 Since E. coli counts varied throughout the day, we wanted to examine the dynamics of bacterial

260 communities. We used the same water samples to conduct deep amplicon sequencing. In

261 agricultural sites and across seasons, clusters clearly stood out from each other suggesting a more

262 or less steady microbial community all day long (Fig 3A). While clusters were also found in

263 urban sites, these data points were more spread out within the groups with some overlap in the

264 community composition (Fig 3B). Factors such as water use, runoff, possible leaking of

265 wastewater or seepage (Vermonden 2010; Vermonden et al. 2009) may explain such

266 perturbations (Fig 3B). Results from the 16S rRNA gene sequencing and top 50 OTUs at the

267 family level are depicted in Fig 4. Enterobacteriaceae constituted a relatively small fraction

$268(<1 \%)$ of the total microbial community. Relative abundance values of $0.06 \%$ and $0.76 \%$ were

269 observed for this family in AGR (Fig 4A) and URB (Fig 4B), respectively. Although E. coli was

270 detected using both the uidA qPCR and testing methods, it could not be detected using deep

271 amplicon sequencing. This observation, not only for E.coli but also for other sequences, may be

272 related to amplicon fragment size (254 bp). This may be a limitation to obtaining sufficient

273 genetic information (Calus et al. 2018) to identify bacteria at the genus or species level. 
275 In the agricultural study site, two clusters were observed for bacterial communities between Q4

276 (fall) and Q3 (summer), Q2 (spring) and Q1 (winter). Within this latter group, 3 sub-groups were

277 identified. In both sampling sites, the most abundant OTUs were in the family Comamonadaceae

278 with average values across seasons of $28.1 \%$ and $18.9 \%$ for AGR and URB, respectively. Similar

279 estimates have been reported for this family in aquatic systems impacted by urbanization or

280 agricultural activities (Griffin et al. 2017; Lopes et al. 2016; Newton \& McLellan 2015; Willems

281 2014). Although Comamonadaceae was predominant across seasons, different patterns were

282 observed for this family. For example, in AGR, a higher abundance of Comamonadaceae was

283 observed during Q3, while members of this family were more abundant during Q4 in URB. A

284 possible explanation for these patterns is the manure application occurring on study site farms

285 during this part of the year (summer) and weather related runoff into the sampling site. In URB,

286 a higher abundance of Comamonadaceae was observed in Q4, corresponding to the onset of the

287 rainy season with storm water runoff in the region. While not considered human pathogens, two

288 genera (Xylophilus and some species of Acidovorax) within this family affect plants (Willems

2014). Other relevant major families $(\geq 4 \%)$ observed in AGR were Flavobacteriaceae (6.7\%),

290 Crenotrichaceae (5.4\%) and Campylobacteraceae (4.3\%). Members of the first two families are

291 widely distributed in the environment (McBride 2014; Siljanen et al. 2011; Urios et al. 2006),

292 with similar estimates being reported in agricultural settings (Pandey et al. 2018; Shawkey et al.

293 2009) and water-sediment interfaces (Chidamba \& Korsten 2015; Frindte et al. 2016). On the

294 other hand, some members of Campylobacteraceae such as Campylobacter and Arcobacter

295 contain species that are well-known human pathogens (Lastovica et al. 2014; Lehner et al. 2005).

296 Although Campylobacteraceae was detected in both sites, we observed an average of ten-fold

297 difference between AGR (4.1\%)(Fig 4A) and URB (0.4\%) (data not shown). Interestingly, the 
relative abundance of Campylobacteraceae in AGR was at least twice as high during Q1 (winter) compared to the other seasons (Fig 4A), with no major changes observed in URB. Note that members of Campylobacteraceae are livestock and poultry associated (Mughini Gras et al. 2012), both of which are farmed in the study area. This Campylobacteraceae prevalence, concentration and survival during winter compared to other seasons in AGR, may be associated to with their sensitivity to desiccation during drier months (Smith et al. 2016), occurrence of heavy rainfall (Ahmed et al. 2013; Moriarty et al. 2011), their presence in waterfowl feces (Moriarty et al. 2012), or various farming practices (Rapp et al. 2014). Alternatively this could also represent detection of material from bacterial lysis (Feng et al. 2017). Another family observed with high relative abundance (10-30\%) in AGR was Phormidiaceae but this family was only abundant during fall (Q4), and completely absent or in very low abundance during other seasons (Fig 4A). Members of this family are common in poor quality streams with precipitation triggering its bloom during fall (Hossain et al. 2012; Kaestli et al. 2017).

It is important to mention that in URB fecally-associated bacteria such as Prevotella (2.20\%), Bacteroides (1.29\%), Blautia (0.76\%), Faecalibacterium (0.57\%) and Coprococcus $(0.24 \%)$ were observed (Figs 4B and 5). These genera have been proposed as potential indicators of sewage and human fecal contamination (Eren et al. 2015; Fisher et al. 2015; Fogarty \& Voytek 2005; McLellan et al. 2013). Significant positive correlations were detected among these genera $(r \geq 0.5137, \mathrm{p}<0.001)$. Major peaks on these genera of bacteria in URB occurred in Q1 during 8 AM and 2 PM (PST) (Fig 5). Moreover, a relatively high abundance of these genera was observed during Q2, Q3 and Q4 between 2 PM and 4PM. Besides precipitation (17.8 mm) in URB during Q1, these observations may represent water use (i.e. flushing events) occurring during the day; with the latter time reflecting changes associated to daylight saving time. When 
321

322

323

324

325

326

327

328

329

330

331

332

333

334

compared to the agricultural watershed, Prevotella, Bacteroides, and Coprococcus were present in AGR, but in combination these genera made up less than $0.23 \%$ of the total microbial community. We observed a positive correlation between Prevotella and Bacteroides $(r<0.7479$, p $<0.001)$. Genera such as Blautia and Faecalibacterium were not detected in AGR using with deep amplicon sequencing.

The prevalence of Prevotella and Bacteroides in URB may also reflect biomarkers of the sampled urban setting (Gorvitovskaia et al. 2016). Another relevant taxa reported to be part of the human gut microbiome (Arumugam et al. 2011) and observed in our study was Ruminococcus. However, low average values of $0.07 \%$ and $0.10 \%$ were found for AGR and URB, respectively. The fact that no major differences between sites were observed across seasons for Ruminococcus may indicate either an anthropogenic influence occurring in AGR. We also cannot rule out wildlife as contributor of this genera (Arumugam et al. 2011). Overall, genera such Prevotella and Bacteroides were present in higher relative abundance in URB compared to the other fecally associated bacteria. These two genera have been proposed as alternative indicator to assess water quality impacted by anthropogenic activities (Fogarty \& Voytek 2005).

To potentially identify novel biomarkers of water quality more detectable than E.coli, additional correlation analyses were conducted with the 10 more abundant bacterial families in each watershed and physico-chemical water quality parameters (Fig 6). In AGR and URB sites there was a moderate to strong positive correlation among variables such as $16 \mathrm{~S}$ rRNA, uidA gene, $E$. coli colonies and total coliforms (as measured by Colilert) (Fig 6). Among these variables, 16S rRNA gene copy numbers were positively correlated with Comamonadaceae, the most abundant bacteria detected in AGR and URB by deep amplicon sequencing. Moreover, water quality 
344

345

346

347

348

349

350

351

352

353

354

355

356

357

358

359

360

361

362

363

364

365

366

parameters related with conductivity (specific conductivity, salinity, total dissolved solids, and oxidation-reduction potential) were positively $(\mathrm{p}<0.0001)$ correlated with Comamonadaceae. In contrast, this family was negatively correlated with dissolved oxygen (DO). This distinguishable pattern has also been reported for Comamonadaceae in anthropogenic impacted aquatic systems (Aguirre et al. 2017).

Temperature had a positive correlation with Comamonadaceae and a negative correlation with Crenotrichaceae in both watersheds. In AGR, $\mathrm{pH}$ was significantly correlated with seven of the most abundant families including Crenotrichaceae, Phormidiaceae, Actinomycetales, Oxalobacteraceae, Helicobacteraceae, Gallionellaceae, Methylophilaceae. Moderate changes in pH may cause community shifts especially in less abundant groups of bacteria or pH-susceptible groups (Krause et al. 2012) as the ones described in our study. Similar to the observations reported by Krause et al. 2012, pH did not have a significant effect on the overall bacterial abundance in both watersheds as estimated by the 16S rRNA gene (Fig 6).

Dissolved oxygen and precipitation were parameters highly correlated between them in both watersheds. This association was reflected by members of the Crenotrichaceae family in AGR and URB. Other families associated to these 2 variables and mostly positively associated between them included Flavobacteriaceae, Prevotellaceae, Lachnospiraceae, a proposed novel bacterial division BD4-9 (possibly from the phylum Verrucomicrobia) (Briee et al. 2007; Derakshani et al. 2001), Bacteroidaceae and Moraxellaceae in URB. These latter two families were positively and strongly correlated between each other in URB $\left(\mathrm{r}_{\mathrm{S}}=0.8103\right.$, p-value $\left.<0.0001\right)$ and AGR $\left(\mathrm{r}_{\mathrm{S}}=0.8319\right.$, $\mathrm{p}$-value $\left.<0.0001\right)$. Additional positive associations between bacteria from fecal origin in URB such as Lachnospiraceae, Bacteroidaceae and Prevotellaceae were also determined by correlation analysis (Fig 6B), and may reflect the microbiome of human 
367 populations and in particular, sewage (McLellan et al. 2013; Newton \& McLellan 2015).

368 Although multiple correlations were observed in the present study, we only described relevant associations that governed the most abundant microbes in AGR and URB (Fig 6).

\section{Conclusions}

372 Metagenomic analysis of bacterial communities indicated fairly stable patterns, while E. coli

373 counts varied widely over time. A moderate correlation was detected between culturable E. coli

374 (as measured by Colilert) and uidA gene. Nevertheless, a difference of 2 orders of magnitude was

375 observed between these approaches. The structure of microbial communities did not change

376 significantly on an hourly basis, however dramatic changes were observed across seasons in the

377 two study locations. Although each watershed exhibited different microbial profile patterns,

378 Comamonadaceae was the most abundant bacteria detected in both watersheds by 16S rRNA

379 gene deep sequencing. Relative abundance of Campylobacteraceae indicated a ten-fold

380 difference between AGR (4.1\%) and URB (0.4\%). Moreover, members of the family

381 Enterobacteriaceae made up less than $1 \%$ of the total microbial community in AGR and URB.

382 In this context, E. coli could not even be detected at the genus level. Genera such Prevotella and

383 Bacteroides were present in higher relative abundance in URB compared to other fecally

384 associated bacteria, which may suggest alternatives in the search for better biomarkers of fecal

385 pollution. Precipitation and DO were positively correlated with seven of the most abundant

386 bacterial families in URB, while that in AGR, $\mathrm{pH}$ was positively correlated with the same

387 number of families. Besides a taxa-based approach such as $16 \mathrm{~S}$ rRNA gene sequencing, the use

388 of metagenomics may be an opportunity to discover better fecal pollution biomarkers. Discovery

389 approaches could include use of taxonomic information but also information at the metabolic and 
functional level (Simon \& Daniel 2011). Although it has been demonstrated that microbial communities may change over short distances $(10 \mathrm{~km})$ (Hewson et al. 2006), we found that the see notable differences comparing across seasons. As the accepted standard for measuring watershed health, it would be ideal to have a more somewhat less variable (counts differed

400 Author Contributions

401 Conceptualization: Miguel I. Uyaguari-Diaz, Matthew A. Croxen, Natalie A. Prystajecky, 402 Patrick Tang.

Data curation: Matthew A. Croxen, Miguel I. Uyaguari-Diaz, Kirby Cronin, Zhiyao Luo.

Formal analysis: Miguel I. Uyaguari-Diaz, Matthew A. Croxen.

Funding acquisition: Judith Isaac-Renton, Patrick Tang.

Investigation: Miguel I. Uyaguari-Diaz, Matthew A. Croxen.

407 Methodology: Miguel I. Uyaguari-Diaz, Matthew A. Croxen, Kirby Cronin, Zhiyao Luo. 
Software: Miguel I. Uyaguari-Diaz, Matthew A. Croxen.

Supervision: Judith Isaac-Renton, Natalie A. Prystajecky, Patrick Tang.

Validation: Miguel I. Uyaguari-Diaz, Matthew A. Croxen.

Visualization: Miguel I. Uyaguari-Diaz, Matthew A. Croxen.

Writing - original draft: Miguel I. Uyaguari-Diaz, Matthew A. Croxen.

Writing - review \& editing: Miguel I. Uyaguari-Diaz, Matthew A. Croxen, Kirby Cronin,

Zhiyao Luo, Judith Isaac-Renton, Natalie A. Prystajecky, Patrick Tang.

\section{Acknowledgements}

We would like to thank Bridget Lee, Michael Peabody, Thea van Rossum, Alvin Xian, Mitchell

Burton, Sara Tan and Tyler Nelson for help with the water sampling. We would also like to

thank Dr. Fiona Brinkman (Simon Fraser University) for providing the mock community.

\section{References}

Aguirre M, Abad D, Albaina A, Cralle L, Goni-Urriza MS, Estonba A, and Zarraonaindia I. 2017. Unraveling the environmental and anthropogenic drivers of bacterial community changes in the Estuary of Bilbao and its tributaries. PLoS One 12:e0178755. 10.1371/journal.pone.0178755

Ahmed MF, Schulz J, and Hartung J. 2013. Survival of Campylobacter jejuni in naturally and artificially contaminated laying hen feces. Poult Sci 92:364-369. 10.3382/ps.2012-02496

APHA. 2005. Standard methods for the examination of water and wastewater. Washington, DC.: American Public Health Association, American Water Works Association and Water Environment Federation.

Arumugam M, Raes J, Pelletier E, Le Paslier D, Yamada T, Mende DR, Fernandes GR, Tap J, Bruls T, Batto JM, Bertalan M, Borruel N, Casellas F, Fernandez L, Gautier L, Hansen T, Hattori M, Hayashi T, Kleerebezem M, Kurokawa K, Leclerc M, Levenez F, Manichanh C, Nielsen HB, Nielsen T, Pons N, Poulain J, Qin J, Sicheritz-Ponten T, Tims S, Torrents D, Ugarte E, Zoetendal EG, Wang J, Guarner F, Pedersen O, de Vos WM, Brunak S, Dore J, Meta HITC, Antolin M, Artiguenave F, Blottiere HM, Almeida M, Brechot C, 
C, van de Guchte M, Guedon E, Haimet F, Huber W, van Hylckama-Vlieg J, Jamet A, Juste C, Kaci G, Knol J, Lakhdari O, Layec S, Le Roux K, Maguin E, Merieux A, Melo Minardi R, M'Rini C, Muller J, Oozeer R, Parkhill J, Renault P, Rescigno M, Sanchez N, Sunagawa S, Torrejon A, Turner K, Vandemeulebrouck G, Varela E, Winogradsky Y, Zeller G, Weissenbach J, Ehrlich SD, and Bork P. 2011. Enterotypes of the human gut microbiome. Nature 473:174-180. 10.1038/nature09944

Aulenbach BT. 2010. Bacteria holding times for fecal coliform by mFC agar method and total coliform and Escherichia coli by Colilert-18 Quanti-Tray method. Environ Monit Assess 161:147-159. 10.1007/s10661-008-0734-3

Bartram J, and Rees G. 2000. Monitoring bathing waters: a practical guide to the design and implementation of assessments and monitoring programmes. London, UK: E \& FN Spon.

BC. 2017. BC recreational water quality guidelines: guidelines summary. In: branch WqaasWpas, editor. Victoria, BC: British Columbia Ministry of Environment and Climate Change Strategy. p 13.

Bokulich NA, Subramanian S, Faith JJ, Gevers D, Gordon JI, Knight R, Mills DA, and Caporaso JG. 2013. Quality-filtering vastly improves diversity estimates from Illumina amplicon sequencing. Nat Methods 10:57-59. 10.1038/nmeth.2276

Bolger AM, Lohse M, and Usadel B. 2014. Trimmomatic: a flexible trimmer for Illumina sequence data. Bioinformatics 30:2114-2120. 10.1093/bioinformatics/btu170

Briee C, Moreira D, and Lopez-Garcia P. 2007. Archaeal and bacterial community composition of sediment and plankton from a suboxic freshwater pond. Res Microbiol 158:213-227. 10.1016/j.resmic.2006.12.012

Byappanahalli MN, and Fujioka RS. 1998. Evidence that tropical soil environment can support the growth of Escherichia coli. Water Science and Technology 38:171-174. https://doi.org/10.1016/S0273-1223(98)00820-8

Calus ST, Ijaz UZ, and Pinto AJ. 2018. NanoAmpli-Seq: A workflow for amplicon sequencing from mixed microbial communities on the nanopore sequencing platform. bioRxiv. $10.1101 / 244517$

Canada H. 2012. Guidelines for Canadian recreational water quality. . Third ed. Ottawa, Ontario: Minister of Health. p 4.

Caporaso JG, Bittinger K, Bushman FD, DeSantis TZ, Andersen GL, and Knight R. 2010a. PyNAST: a flexible tool for aligning sequences to a template alignment. Bioinformatics 26:266-267. 10.1093/bioinformatics/btp636

Caporaso JG, Kuczynski J, Stombaugh J, Bittinger K, Bushman FD, Costello EK, Fierer N, Pena AG, Goodrich JK, Gordon JI, Huttley GA, Kelley ST, Knights D, Koenig JE, Ley RE, Lozupone CA, McDonald D, Muegge BD, Pirrung M, Reeder J, Sevinsky JR, Turnbaugh PJ, Walters WA, Widmann J, Yatsunenko T, Zaneveld J, and Knight R. 2010b. QIIME allows analysis of high-throughput community sequencing data. Nat Methods 7:335-336. 10.1038/nmeth.f.303

Caporaso JG, Lauber CL, Walters WA, Berg-Lyons D, Huntley J, Fierer N, Owens SM, Betley J, Fraser L, Bauer M, Gormley N, Gilbert JA, Smith G, and Knight R. 2012. Ultra-highthroughput microbial community analysis on the Illumina HiSeq and MiSeq platforms. ISME J 6:1621-1624. 10.1038/ismej.2012.8

Chidamba L, and Korsten L. 2015. Pyrosequencing analysis of roof-harvested rainwater and river water used for domestic purposes in Luthengele village in the Eastern Cape Province of South Africa. Environ Monit Assess 187:41. 10.1007/s10661-014-4237-0 
Clermont O, Gordon DM, Brisse S, Walk ST, and Denamur E. 2011. Characterization of the cryptic Escherichia lineages: rapid identification and prevalence. Environ Microbiol 13:2468-2477. 10.1111/j.1462-2920.2011.02519.x

Croxen MA, and Finlay BB. 2010. Molecular mechanisms of Escherichia coli pathogenicity. Nat Rev Microbiol 8:26-38. 10.1038/nrmicro2265

Derakshani M, Lukow T, and Liesack W. 2001. Novel bacterial lineages at the (sub)division level as detected by signature nucleotide-targeted recovery of $16 \mathrm{~S}$ rRNA genes from bulk soil and rice roots of flooded rice microcosms. Appl Environ Microbiol 67:623-631. 10.1128/AEM.67.2.623-631.2001

DeSantis TZ, Hugenholtz P, Larsen N, Rojas M, Brodie EL, Keller K, Huber T, Dalevi D, Hu P, and Andersen GL. 2006. Greengenes, a chimera-checked 16S rRNA gene database and workbench compatible with ARB. Appl Environ Microbiol 72:5069-5072. 10.1128/AEM.03006-05

Edgar RC. 2010. Search and clustering orders of magnitude faster than BLAST. Bioinformatics 26:2460-2461. 10.1093/bioinformatics/btq461

Eren AM, Sogin ML, Morrison HG, Vineis JH, Fisher JC, Newton RJ, and McLellan SL. 2015. A single genus in the gut microbiome reflects host preference and specificity. ISME J 9:90-100. 10.1038/ismej.2014.97

Feng J, Ma L, Nie J, Konkel ME, and Lu X. 2017. Environmental stress-induced bacterial lysis and extracellular DNA release contribute to Campylobacter jejuni biofilm formation. Appl Environ Microbiol. 10.1128/AEM.02068-17

Ferguson D, and Signoretto C. 2011. Environmental Persistence and Naturalization of Fecal Indicator Organisms. In: Hagedorn C, Blanch AR, and Harwood VJ, eds. Microbial Source Tracking: Methods, Applications, and Case Studies. New York, NY: Springer New York, 379-397.

Ferris MJ, Muyzer G, and Ward DM. 1996. Denaturing gradient gel electrophoresis profiles of $16 \mathrm{~S}$ rRNA-defined populations inhabiting a hot spring microbial mat community. Appl Environ Microbiol 62:340-346.

Fisher JC, Eren AM, Green HC, Shanks OC, Morrison HG, Vineis JH, Sogin ML, and McLellan SL. 2015. Comparison of Sewage and Animal Fecal Microbiomes by Using Oligotyping Reveals Potential Human Fecal Indicators in Multiple Taxonomic Groups. Appl Environ Microbiol 81:7023-7033. 10.1128/AEM.01524-15

Fogarty LR, and Voytek MA. 2005. Comparison of bacteroides-prevotella 16S rRNA genetic markers for fecal samples from different animal species. Appl Environ Microbiol 71:5999-6007. 10.1128/AEM.71.10.5999-6007.2005

Frahm E, and Obst U. 2003. Application of the fluorogenic probe technique (TaqMan PCR) to the detection of Enterococcus spp. and Escherichia coli in water samples. J Microbiol Methods 52:123-131.

Frindte K, Allgaier M, Grossart H-P, and Eckert W. 2016. Redox stability regulates community structure of active microbes at the sediment-water interface. Environmental Microbiology Reports 8:798-804. 10.1111/1758-2229.12441

Gorvitovskaia A, Holmes SP, and Huse SM. 2016. Interpreting Prevotella and Bacteroides as biomarkers of diet and lifestyle. Microbiome 4:15. 10.1186/s40168-016-0160-7

Griffin JS, Lu N, Sangwan N, Li A, Dsouza M, Stumpf AJ, Sevilla T, Culotti A, Keefer LL, Kelly JJ, Gilbert JA, Wells GF, and Packman AI. 2017. Microbial diversity in an 
intensively managed landscape is structured by landscape connectivity. FEMS Microbiol Ecol 93. 10.1093/femsec/fix120

Haas BJ, Gevers D, Earl AM, Feldgarden M, Ward DV, Giannoukos G, Ciulla D, Tabbaa D, Highlander SK, Sodergren E, Methe B, DeSantis TZ, Human Microbiome C, Petrosino JF, Knight R, and Birren BW. 2011. Chimeric 16S rRNA sequence formation and detection in Sanger and 454-pyrosequenced PCR amplicons. Genome Res 21:494-504. 10.1101/gr.112730.110

Harms G, Layton AC, Dionisi HM, Gregory IR, Garrett VM, Hawkins SA, Robinson KG, and Sayler GS. 2003. Real-time PCR quantification of nitrifying bacteria in a municipal wastewater treatment plant. Environ Sci Technol 37:343-351.

Hewson I, Steele JA, Capone DG, and Fuhrman JA. 2006. Temporal and spatial scales of variation in bacterioplankton assemblages of oligotrophic surface waters. Marine Ecology Progress Series 311:67-77.

Hossain MY, Jewel MAS, Fulanda B, Ahamed F, Rahman S, Jasmine S, and Ohtomi J. 2012. Dynamics of cyanobacteria Planktothrix species (Oscillatoriales: Phormidiaceae) in earthen fish ponds, northwestern Bangladesh.

Isobe KO, Tarao M, Chiem NH, Minh le Y, and Takada H. 2004. Effect of environmental factors on the relationship between concentrations of coprostanol and fecal indicator bacteria in tropical (Mekong Delta) and temperate (Tokyo) freshwaters. Appl Environ Microbiol 70:814-821.

Kaestli M, Skillington A, Kennedy K, Majid M, Williams D, McGuinness K, Munksgaard N, and Gibb K. 2017. Spatial and Temporal Microbial Patterns in a Tropical Macrotidal Estuary Subject to Urbanization. Front Microbiol 8:1313. 10.3389/fmicb.2017.01313

Kaper JB, Nataro JP, and Mobley HL. 2004. Pathogenic Escherichia coli. Nat Rev Microbiol 2:123-140. 10.1038/nrmicro818

Krause E, Wichels A, Giménez L, Lunau M, Schilhabel MB, and Gerdts G. 2012. Small Changes in $\mathrm{pH}$ Have Direct Effects on Marine Bacterial Community Composition: A Microcosm Approach. PLoS One 7:e47035. 10.1371/journal.pone.0047035

Lane D. 1991. 16S/23S rRNA sequencing. Nucleic acid techniques in bacterial systematics:125175.

Lastovica AJ, On SLW, and Zhang L. 2014. The Family Campylobacteraceae. In: Rosenberg E, DeLong EF, Lory S, Stackebrandt E, and Thompson F, eds. The Prokaryotes: Deltaproteobacteria and Epsilonproteobacteria. Berlin, Heidelberg: Springer Berlin Heidelberg, 307-335.

Lee ZM, Bussema C, 3rd, and Schmidt TM. 2009. rrnDB: documenting the number of rRNA and tRNA genes in bacteria and archaea. Nucleic Acids Res 37:D489-493. 10.1093/nar/gkn689

Lehner A, Tasara T, and Stephan R. 2005. Relevant aspects of Arcobacter spp. as potential foodborne pathogen. Int J Food Microbiol 102:127-135. 10.1016/j.ijfoodmicro.2005.03.003

Levesque B, and Gauvin D. 2007. Microbiological guideline values for recreational bathing in Canada: Time for change? Can J Infect Dis Med Microbiol 18:153-157.

Lopes FA, Catao EC, Santana RH, Cabral Ade S, Paranhos R, Rangel TP, de Rezende CE, Edwards RA, Thompson CC, Thompson FL, and Kruger RH. 2016. Microbial Community Profile and Water Quality in a Protected Area of the Caatinga Biome. PLoS One 11:e0148296. 10.1371/journal.pone.0148296 
612

613

614

615

616

617

618

Mac Kenzie WR, Hoxie NJ, Proctor ME, Gradus MS, Blair KA, Peterson DE, Kazmierczak JJ, Addiss DG, Fox KR, Rose JB, and et al. 1994. A massive outbreak in Milwaukee of cryptosporidium infection transmitted through the public water supply. $N$ Engl J Med 331:161-167. 10.1056/NEJM199407213310304

Maheux AF, Bissonnette L, Boissinot M, Bernier JL, Huppe V, Picard FJ, Berube E, and Bergeron MG. 2011. Rapid concentration and molecular enrichment approach for sensitive detection of Escherichia coli and Shigella species in potable water samples. Appl Environ Microbiol 77:6199-6207. 10.1128/AEM.02337-10

Maier A, Krolik J, Fan S, Quintin P, McGolrick D, Joyce A, and Majury A. 2015. Evaluating appropriate maximum holding times for private well water samples. Environmental Health Review 58:35-40. 10.5864/d2015-011

Masella AP, Bartram AK, Truszkowski JM, Brown DG, and Neufeld JD. 2012. PANDAseq: paired-end assembler for illumina sequences. BMC Bioinformatics 13:31. 10.1186/14712105-13-31

McBride MJ. 2014. The Family Flavobacteriaceae. In: Rosenberg E, DeLong EF, Lory S, Stackebrandt E, and Thompson F, eds. The Prokaryotes: Other Major Lineages of Bacteria and The Archaea. Berlin, Heidelberg: Springer Berlin Heidelberg, 643-676.

McLellan SL, Newton RJ, Vandewalle JL, Shanks OC, Huse SM, Eren AM, and Sogin ML. 2013. Sewage reflects the distribution of human faecal Lachnospiraceae. Environ Microbiol 15:2213-2227. 10.1111/1462-2920.12092

Moriarty EM, Mackenzie ML, Karki N, and Sinton LW. 2011. Survival of Escherichia coli, Enterococci, and Campylobacter spp. in sheep feces on pastures. Appl Environ Microbiol 77:1797-1803. 10.1128/AEM.01329-10

Moriarty EM, Weaver L, Sinton LW, and Gilpin B. 2012. Survival of Escherichia coli, enterococci and Campylobacter jejuni in Canada goose faeces on pasture. Zoonoses Public Health 59:490-497. 10.1111/zph.12014

Mughini Gras L, Smid JH, Wagenaar JA, de Boer AG, Havelaar AH, Friesema IH, French NP, Busani L, and van Pelt W. 2012. Risk factors for campylobacteriosis of chicken, ruminant, and environmental origin: a combined case-control and source attribution analysis. PLoS One 7:e42599. 10.1371/journal.pone.0042599

Newton RJ, and McLellan SL. 2015. A unique assemblage of cosmopolitan freshwater bacteria and higher community diversity differentiate an urbanized estuary from oligotrophic Lake Michigan. Front Microbiol 6:1028. 10.3389/fmicb.2015.01028

Nikolenko SI, Korobeynikov AI, and Alekseyev MA. 2013. BayesHammer: Bayesian clustering for error correction in single-cell sequencing. BMC Genomics 14 Suppl 1:S7. 10.1186/1471-2164-14-S1-S7

Noble RT, Blackwood AD, Griffith JF, McGee CD, and Weisberg SB. 2010. Comparison of rapid quantitative PCR-based and conventional culture-based methods for enumeration of Enterococcus spp. and Escherichia coli in recreational waters. Appl Environ Microbiol 76:7437-7443. 10.1128/AEM.00651-10

Oliver DM, Bird C, Burd E, and Wyman M. 2016. Quantitative PCR Profiling of Escherichia coli in Livestock Feces Reveals Increased Population Resilience Relative to Culturable Counts under Temperature Extremes. Environ Sci Technol 50:9497-9505. 10.1021/acs.est.6b02657 
Pandey P, Chiu C, Miao M, Wang Y, Settles M, Del Rio NS, Castillo A, Souza A, Pereira R, and Jeannotte R. 2018. 16S rRNA analysis of diversity of manure microbial community in dairy farm environment. PLoS One 13:e0190126. 10.1371/journal.pone.0190126

Peabody MA, Van Rossum T, Lo R, and Brinkman FS. 2015. Evaluation of shotgun metagenomics sequence classification methods using in silico and in vitro simulated communities. BMC Bioinformatics 16:363. 10.1186/s12859-015-0788-5

Pope ML, Bussen M, Feige MA, Shadix L, Gonder S, Rodgers C, Chambers Y, Pulz J, Miller K, Connell K, and Standridge J. 2003. Assessment of the effects of holding time and temperature on Escherichia coli densities in surface water samples. Appl Environ Microbiol 69:6201-6207.

Price MN, Dehal PS, and Arkin AP. 2010. FastTree 2--approximately maximum-likelihood trees for large alignments. PLoS One 5:e9490. 10.1371/journal.pone.0009490

Rapp D, Ross CM, Cave V, and Muirhead RW. 2014. Prevalence, concentration and genotypes of Campylobacter jejuni in faeces from dairy herds managed in farm systems with or without housing. J Appl Microbiol 116:1035-1043. 10.1111/jam.12425

Rideout JR, He Y, Navas-Molina JA, Walters WA, Ursell LK, Gibbons SM, Chase J, McDonald D, Gonzalez A, Robbins-Pianka A, Clemente JC, Gilbert JA, Huse SM, Zhou HW, Knight R, and Caporaso JG. 2014. Subsampled open-reference clustering creates consistent, comprehensive OTU definitions and scales to billions of sequences. PeerJ 2:e545. 10.7717/peerj.545

Ritalahti KM, Amos BK, Sung Y, Wu Q, Koenigsberg SS, and Loffler FE. 2006. Quantitative PCR targeting 16S rRNA and reductive dehalogenase genes simultaneously monitors multiple Dehalococcoides strains. Appl Environ Microbiol 72:2765-2774. 10.1128/AEM.72.4.2765-2774.2006

Rochelle-Newall E, Nguyen TM, Le TP, Sengtaheuanghoung O, and Ribolzi O. 2015. A short review of fecal indicator bacteria in tropical aquatic ecosystems: knowledge gaps and future directions. Front Microbiol 6:308. 10.3389/fmicb.2015.00308

Shawkey MD, Firestone MK, Brodie EL, and Beissinger SR. 2009. Avian incubation inhibits growth and diversification of bacterial assemblages on eggs. PLoS One 4:e4522. 10.1371/journal.pone.0004522

Siljanen HMP, Saari A, Krause S, Lensu A, Abell GCJ, Bodrossy L, Bodelier PLE, and Martikainen PJ. 2011. Hydrology is reflected in the functioning and community composition of methanotrophs in the littoral wetland of a boreal lake. FEMS Microbiology Ecology 75:430-445. 10.1111/j.1574-6941.2010.01015.x

Simon C, and Daniel R. 2011. Metagenomic analyses: past and future trends. Appl Environ Microbiol 77:1153-1161. 10.1128/AEM.02345-10

Smith S, Meade J, Gibbons J, McGill K, Bolton D, and Whyte P. 2016. The impact of environmental conditions on Campylobacter jejuni survival in broiler faeces and litter. Infect Ecol Epidemiol 6:31685. 10.3402/iee.v6.31685

Urios L, Agogue H, Lesongeur F, Stackebrandt E, and Lebaron P. 2006. Balneola vulgaris gen. nov., sp. nov., a member of the phylum Bacteroidetes from the north-western Mediterranean Sea. Int J Syst Evol Microbiol 56:1883-1887. 10.1099/ijs.0.64285-0

van Elsas JD, Semenov AV, Costa R, and Trevors JT. 2011. Survival of Escherichia coli in the environment: fundamental and public health aspects. ISME J 5:173-183. 10.1038/ismej.2010.80 
Vermonden K. 2010. Key factors for biodiversity of urban water systems PhD. Radboud University Nijmegen.

Vermonden K, Hermus MAA, van Weperen M, Leuven RSEW, van der Velde G, Smolders AJP, Roelofs JGM, and Hendriks AJ. 2009. Does upward seepage of river water and storm water runoff determine water quality of urban drainage systems in lowland areas? A case study for the Rhine-Meuse delta. Hydrological Processes 23:3110-3120. 10.1002/hyp.7422

Walk ST, Alm EW, Gordon DM, Ram JL, Toranzos GA, Tiedje JM, and Whittam TS. 2009. Cryptic lineages of the genus Escherichia. Appl Environ Microbiol 75:6534-6544. 10.1128/AEM.01262-09

Walker DI, McQuillan J, Taiwo M, Parks R, Stenton CA, Morgan H, Mowlem MC, and Lees DN. 2017. A highly specific Escherichia coli qPCR and its comparison with existing methods for environmental waters. Water Res 126:101-110. 10.1016/j.watres.2017.08.032

Wickham H. 2009. ggplot2 : elegant graphics for data analysis. New York ; London: Springer. Willems A. 2014. The Family Comamonadaceae. In: Rosenberg E, DeLong EF, Lory S, Stackebrandt E, and Thompson F, eds. The Prokaryotes: Alphaproteobacteria and Betaproteobacteria. Berlin, Heidelberg: Springer Berlin Heidelberg, 777-851.

Wohlsen T, Bates J, Vesey G, Robinson WA, and Katouli M. 2006. Evaluation of the methods for enumerating coliform bacteria from water samples using precise reference standards. Lett Appl Microbiol 42:350-356. 10.1111/j.1472-765X.2006.01854.x 


\section{Figure Legends}

688 Fig 1. Sampling locations with land cover. A) Agricultural watershed. B) Urban watershed

689 Fig 2. Scatterplot of $\boldsymbol{E}$. coli colony counts using Colilert. The x-axis represents sample

690 collection time in each quarter (Q1-Q4) and the y-axis depicts the E. coli most probable number

691 (MPN) per $100 \mathrm{ml}$ of water sample. Full red and empty blue circles depict true sample replicates.

692 Red dotted line set at 400 MPN/100 ml represents Health Canada's limit for recreational water

693 quality.

694 Fig 3. Principal coordinate analysis based on Bray-Curtis dissimilarity ( $\beta$-diversity) for the 695 16Sr RNA gene amplicons ( $\mathbf{n = 2 4}$ time points) across seasons (Q1-Q4). A) Agricultural

696 watershed. B) Urban watershed.

697 Fig 4. Heat map depicting the relative abundance of the top 50 most abundant OTUs in

698 agricultural (A) and urban (B) watersheds. Hourly data sets were merged using QIIME, based 699 on categorical data for visualization purposes. The color key at the top represents percentages of 700 relative abundance, while that branches depict hierarchical clustering based on similarity.

701 Fig 5. Line plots of fecally-associated bacteria observed in the urban watershed. The $x$-axis 702 represents sample collection time in each quarter (Q1-Q4) and the y-axis shows percentages of 703 relative abundance.

704 Figure 6. Heat map showing the Spearman's rank correlation analysis between the top 10 705 most abundant families and water quality parameters. A) Agricultural watershed. B) Urban 706 watershed. 


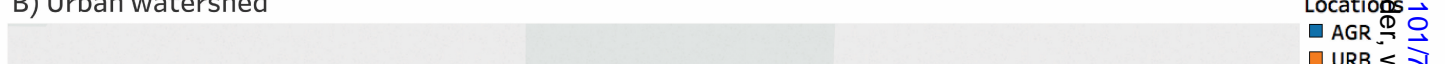


bioRxiv preprint doi: https://doi.org/10.1101/719146; this version posted July 31, 2019. The copyright holder for this preprint (which was not certified by peer review) is the author/funder, who has granted bioRxiv a license to display the preprint in perpetuity. It is made available under aCC-BY-NC-ND 4.0 International license.

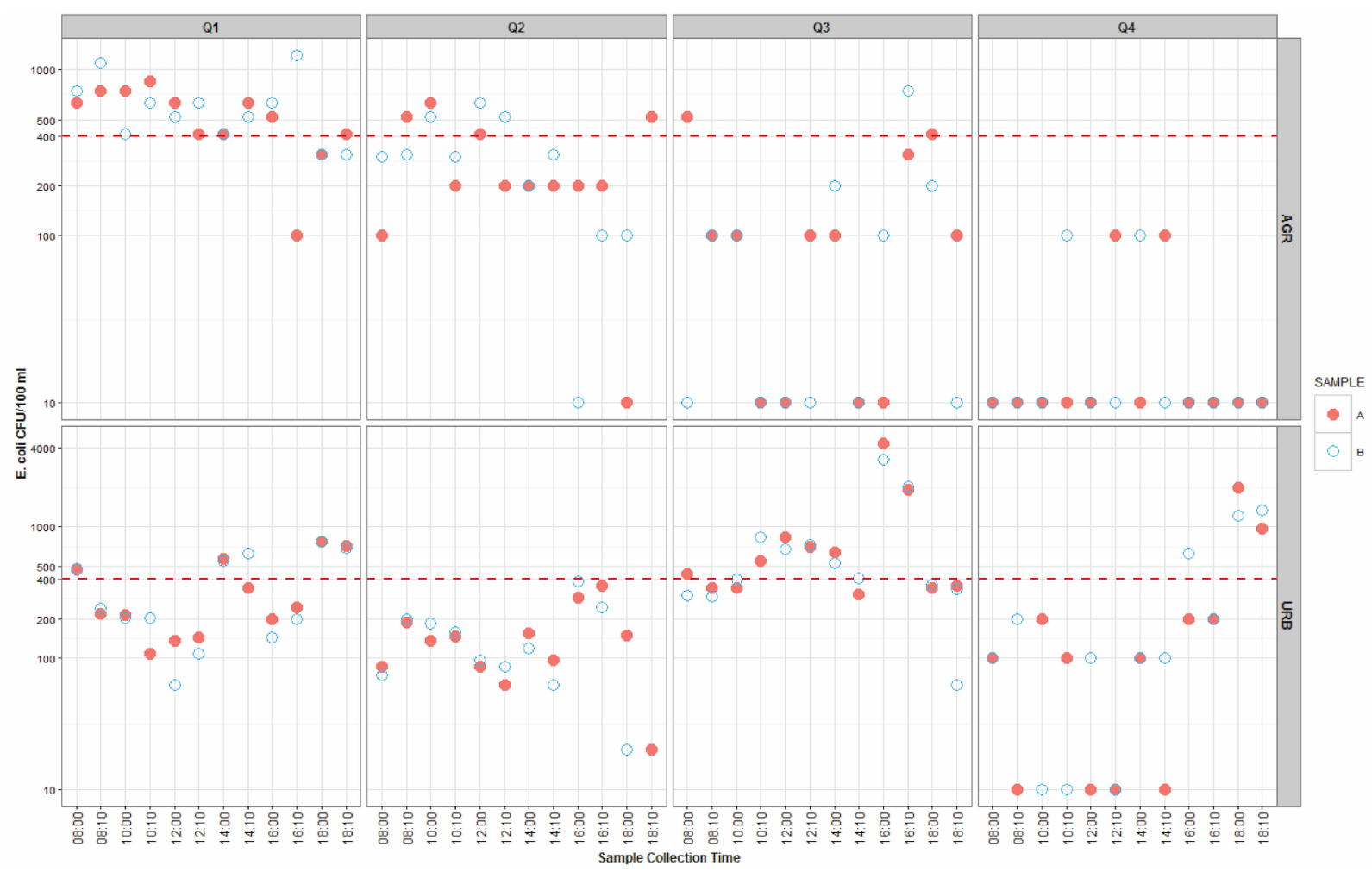


A.

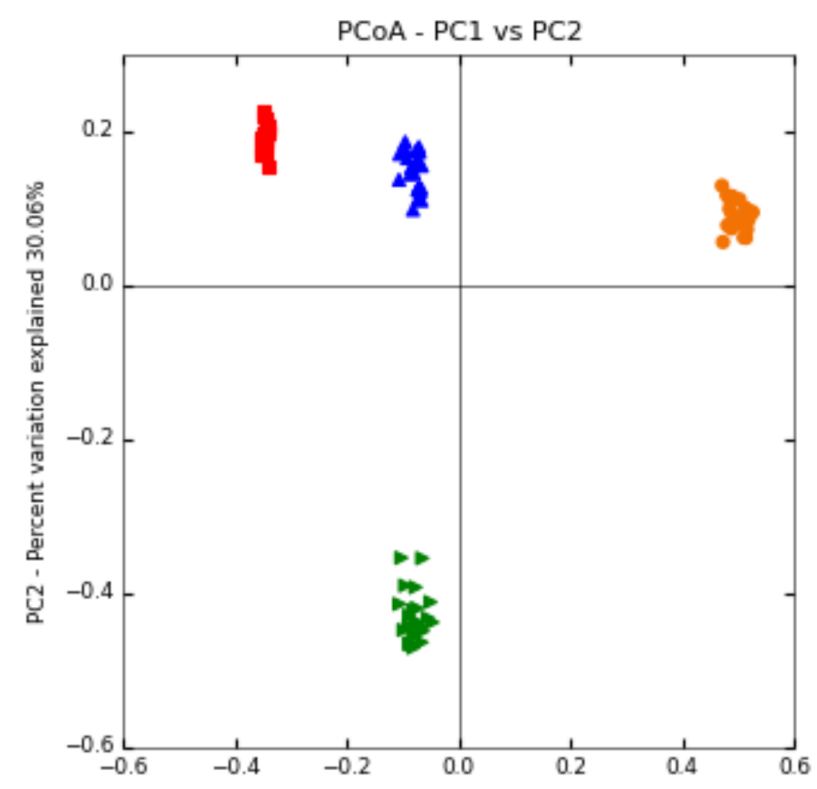

$\mathrm{PC1}$ - Percent variation explained $45.18 \%$

B.

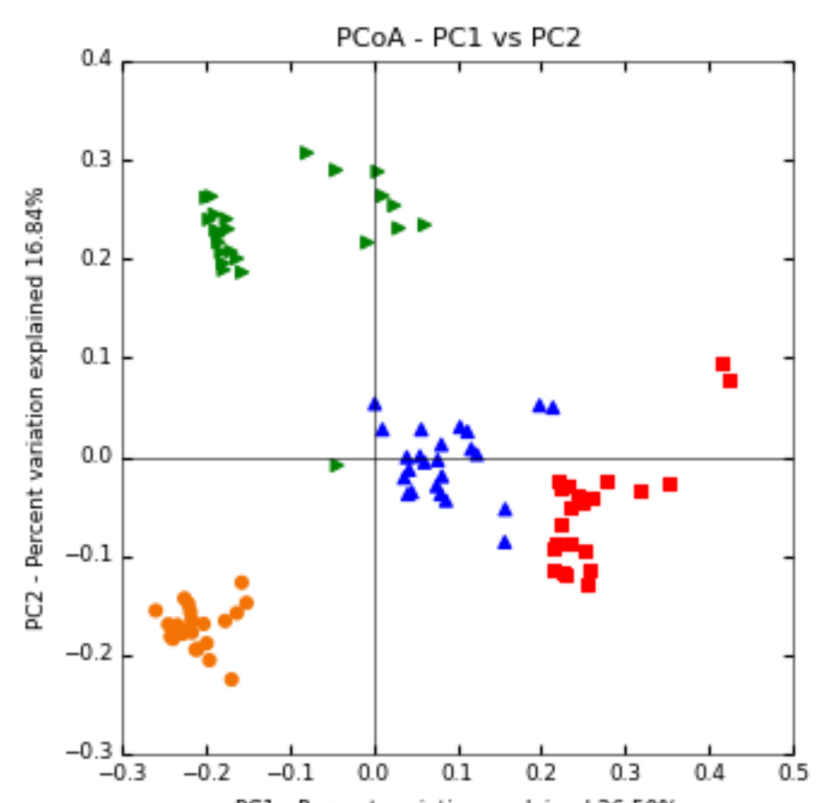

$\mathrm{PCl}$ - Percent variation explained $26.50 \%$

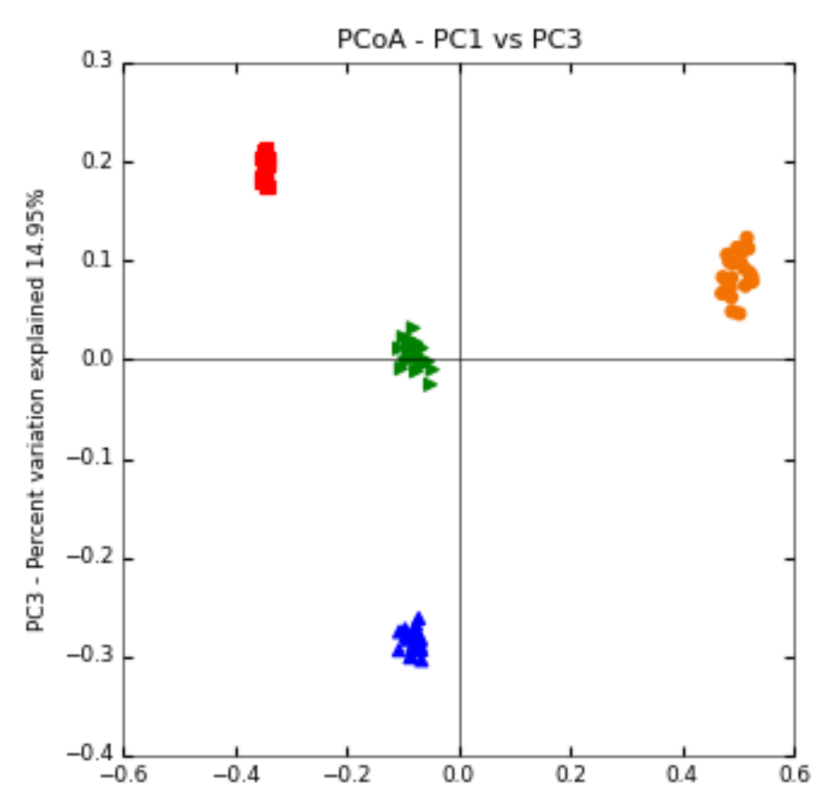

PC1 - Percent variation explained $45.18 \%$

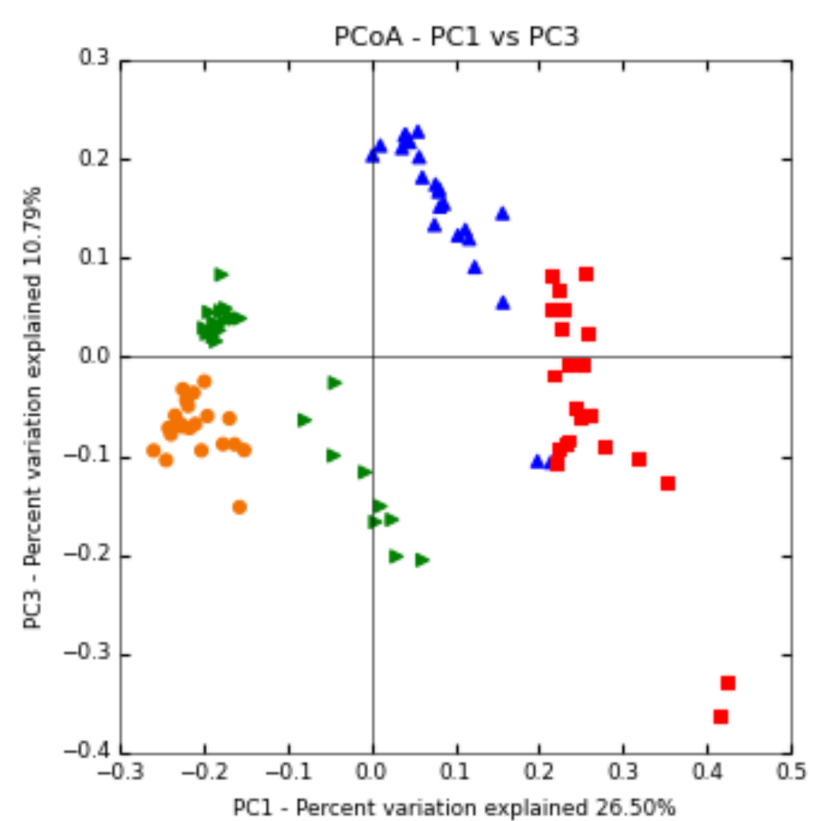

Quarter 1
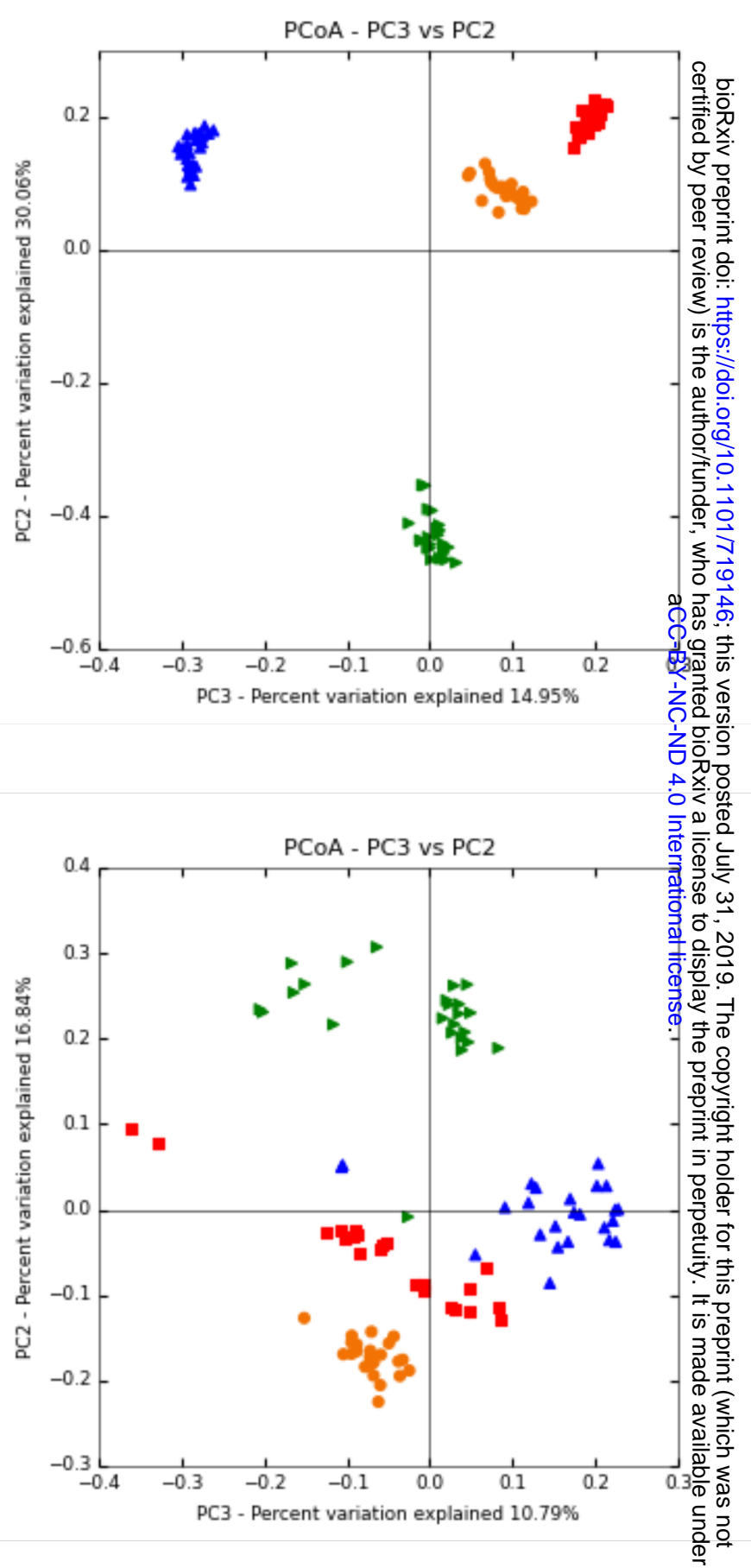

PC3 - Percent variation explained 14.95\%

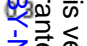

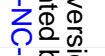

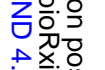

2
0

\section{Quarter 4}



aCC-BY-NC-ND 4.0 International license.

\section{A) Agricultural watershed}

\section{Variables}

Comamonadaceae

Flavobacteriaceae Crenotrichaceae

Phormidiaceae

Actinomycetales

Campylobacteracea Oxalobacteraceae Helicobacteraceae Gallionellaceae Methylophilaceae 16S RRNA

uidA

E. Colli(CFU/100 ml) TC $(C F U / 100 \mathrm{ml})$ $\mathrm{pH}$

Temperature $\left({ }^{\circ} \mathrm{C}\right)$ DO $(m g / l)$

Precipitation $(\mathrm{mm})$ $\operatorname{TDS}(\mathrm{mg} / \mathrm{l})$ $S P C(\mu S / \mathrm{cm})$ Salinity (PSU) Pressure $(\mathrm{mmHg})$ $O R P(m V)$

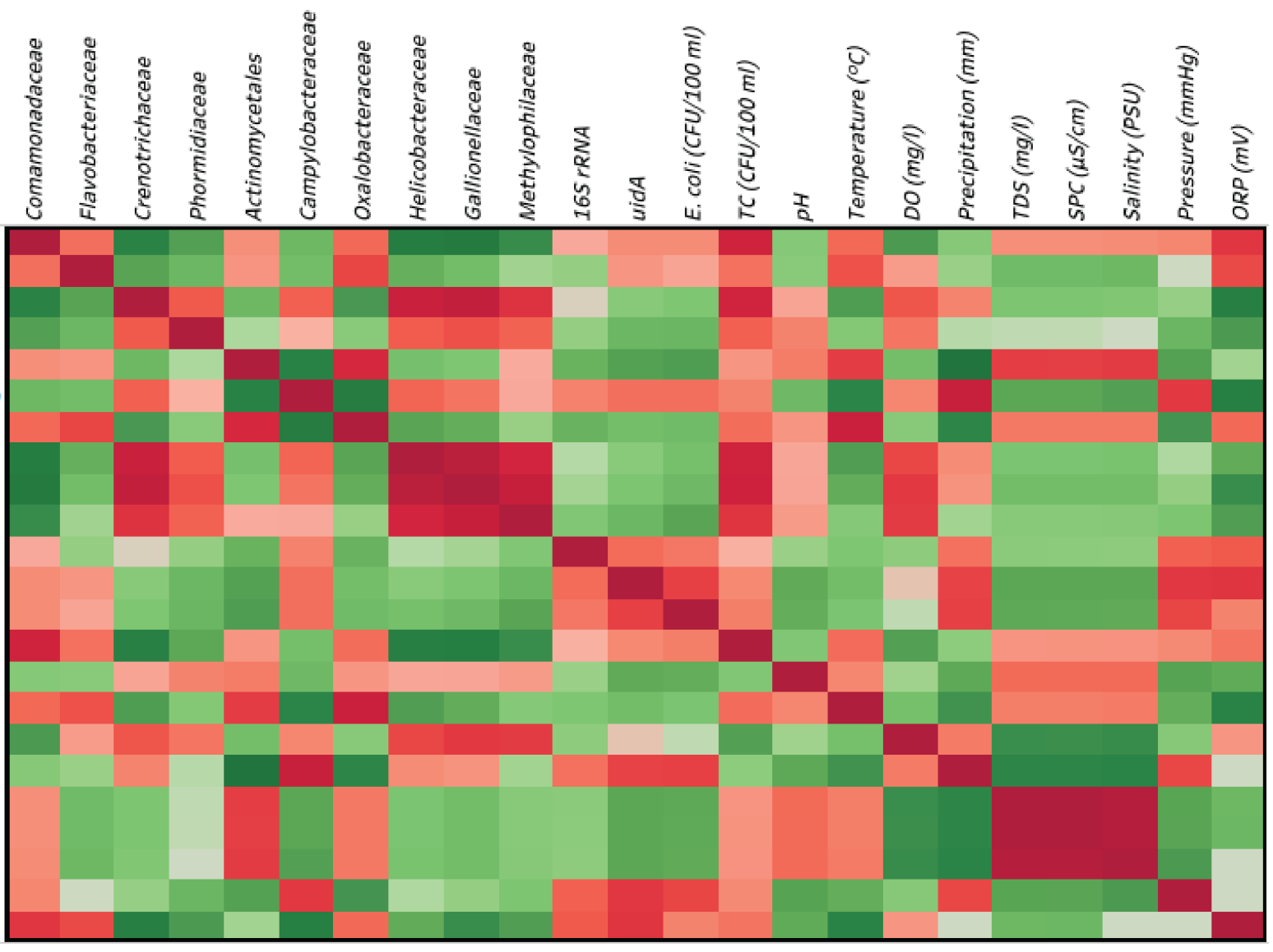

\section{B) Urban watershed}

Variables

Comamonadaceae Other Bacteria Coxiellaceae

Flavobacteriaceae Prevotellaceae Crenotrichaceae Lachnospiraceae C_BD4_9

Bacteroidaceae Moraxellaceae 16S rRNA uidA

E. $\mathrm{COli}(\mathrm{CFU} / 100 \mathrm{ml})$ TC $(\mathrm{CFU} / 100 \mathrm{ml})$ $\mathrm{pH}$

Temperature $\left({ }^{\circ} \mathrm{C}\right)$ $D O(m g / l)$

Precipitation (mm) $T D S(m g / l)$ $S P C(\mu S / \mathrm{cm})$ Salinity (PSU) Pressure $(\mathrm{mmHg})$ $O R P(m V)$

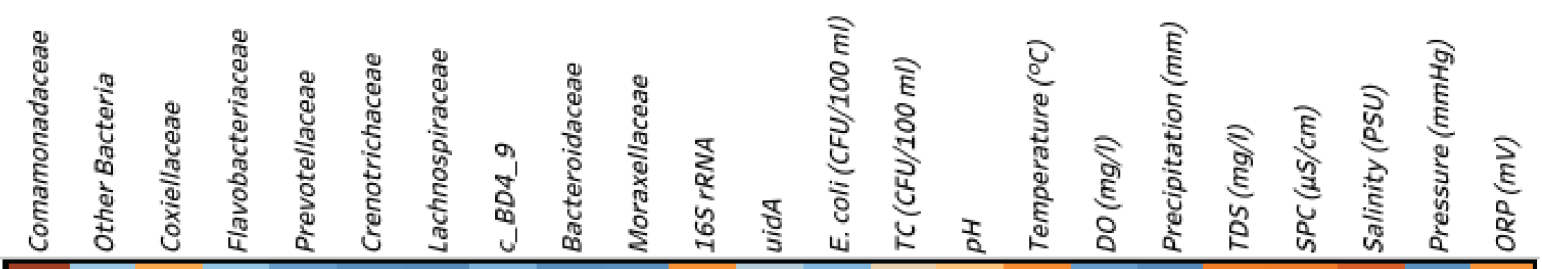

Spearman coefficients $-0.923 \quad 1.000$ 